\title{
Analyzing the Failure of Welded Steel Components in Construction Systems
}

\author{
Daniel J. Thomas
}

Submitted: 8 December 2017/Published online: 18 January 2018

(c) ASM International 2018

\begin{abstract}
Failure of welded construction steel components can occur due to inappropriate design, wrong steel choice or quality, substandard welding processes and through defective maintenance. Welded constructional steel joints in particular are highly sensitive to issues of fatigue, weld corrosion and/or weld quality. A key concern is on placing welds in regions of nominal stress. Welded joints are produced to a specification, which is used to minimize the heat-affected zone and any residual stress within the weld. In this article, numerous examples of weld fracture are shown together with the causes and of weld failure.
\end{abstract}

Keywords Welded joints - Steel structures · Fracture · Fatigue cracks

\section{List of symbols}

$\begin{array}{ll}Y & \text { Shape factor } \\ N & \text { Number of cycles }\end{array}$

$a \& b \quad$ Half-length of the crack

$m \& C \quad$ Constants of paris equation

$\sigma_{m} \sigma_{b} \quad$ Nominal membrane and shell bending stress

$Y_{m} Y_{b} \quad$ Correction function membrane and bending stress intensity factor

$\sigma \quad$ Stress

$\mathrm{d} a / \mathrm{d} N \quad$ Crack growth millimeter per minute

$K \quad$ Stress intensity factor

$G \quad$ Strain energy release rate

D. J. Thomas $(\varangle)$

Creation Engineering Group, Llynfi Enterprise Centre, Heol Ty

Gwyn Industrial Estate, Maesteg, UK

e-mail: daniel.thomas@creationengineering.co.uk
$M_{k, m} \quad$ Correction factor for the local membrane and bending stress concentration due to the weld profile

$M_{k, b} \quad$ Correction factor for the local membrane and bending stress concentration due to the weld profile

$\Delta K \quad$ Change in stress intensity factor

$E \quad$ Young's modulus

$d U \quad$ Strain energy

$d A \quad$ Area of fatigue crack

LEFM Linear elastic fracture mechanics

EPFM Elastic-plastic fracture mechanics

S-N Stress life

E-N Strain life

SHSS Structural hot spot stress

GMAW Gas metal arc welding or

SMAW Shielded metal arc welding

\section{Introduction}

Welded constructional steel structures consist of beams, channels, angles and plates as shown in Fig. 1. These are subsequently joined to each other by bolts, welded joints or rivets. These structures are often subjected to loads that are over that of their designed load, can be in services for many years and have to contend with environmental factors and service factors that produce fluctuating stresses.

A steel component that consists as part of a structure will have an independent structural function. Many of these structural elements are welded together, which make a contribution to the strength, durability and life of the application. Steel structures are subsequently subjected to 

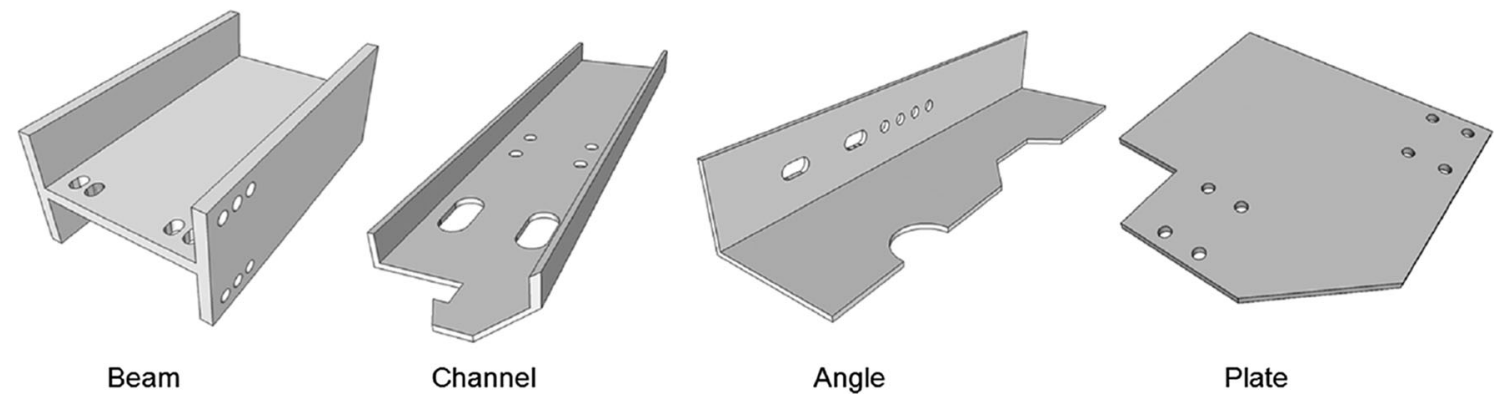

Fig. 1 Typical structural steel components which are welded together during the process of assembly

variable loads and can undergo fatigue failures from the weld [1].

Modern-day welding technology provides an enhanced capacity for the flexible fabrication of different constructional structures. However, despite of this, welded joints can also represent the weakest part of structures and are susceptible to failure. The quality and strength of welded joints depend on factors such as the design, dimensioning and welding processes undertaken during fabrication. It is factors which include inappropriate design (area where welds are placed at an area of high stress), incorrect weld dimension, remaining residual stresses in the joints after welding and metallurgical alterations in the microstructure of the steel and particularly changes in the parent material. It is these key factors which ultimately decrease the life of the structure and eventually lead to the formation of a fracture and subsequent structural failure. The correct design of welded joints requires factors, such as the loading of the joints, the steel type, welding process and the geometry of the structure to be taken into account [2].

In order to ensure the structural integrity of steel components during the life of the structure, it is a requirement to provide a control. This starts at the design phase, through to steel material selection, to weld fabrication and subsequent inspection/maintenance of the application. Stress raising features designed during the initial phases of the realization of the components can have the effect of creating significant problems later on for the application. The wrong choice of steel grade or inappropriate steel chemistry may result in the formation of a brittle heat-affected zone (HAZ) and welding problems such as cracking or insufficient weld penetration. The latter point of weld penetration is very important as weld quality is heavily dependent on the use of heat. This subsequently results in changing the metallurgy of the parent material around the region of the weld. Increasing the heat improves the weld penetration but also increases the size of the HAZ as well as potentially inducing for brittle microstructural phases and tensile residual stresses.

In service, the breakdown of welded structures is typically as a result of fatigue-induced failure. Fatigue cracks are initiated in weld toe, but can also initiate in the weld root and even from discontinuities inside the weld [3]. In order to ensure structural integrity of the application, the initial design phase is the most important for maintaining the life length of the components. However, there are three conditions that have to be met in order to achieve this and it is a case of balancing the following these three conditions:

1. The application must perform its specified functions as efficiently as possible.

2. The application must be capable of providing an adequate service life.

3. The application must be capable of being fabricated economically.

It is the art of balancing these conditions that can cause problems, particularly when cost in brought in as an important factor. Usually, it is the case that safety factors are subsequently reduced to a bare minimum. Because of this reason that approximately $90 \%$ of the failures which occur in constructional steel components is because of the formation of fatigue-induced fractures from welded structures [4].

\section{Weld Stresses}

Currently, there are a number of stress-based approaches that are used to determine the fatigue resistance of welded structures. These are based on extensive tests of welded joints and connections, and these are shown in Fig. 2. Welded joints are classified by the type, loading orientation and characteristic shape. The ability of the weld to withstand certain loading regimes has been determined from laboratory experiments. Here, a number of stress life (S-N) fatigue curves have been generated to confirm that welds of a similar shape have the same general fatigue behavior as that of a real-life weld. Subsequently, when a component is designed, the engineer only needs to understand the nominal stress and select a weld type. Because of this, there is no need to consider the stress concentration effects of the weld. 
When analyzing stresses, the structural stress approach includes macroscopic stress concentrating effects of the weld. However, this method does not consider the local peak stress caused by the notch at the weld toe. The weld toe region as shown in Fig. 3 is, however, very important toward the initiation region of a fatigue crack.

There are numerous methods that are used to determine structural stress. These involve extrapolating both computed and measured stresses from two points near the weld to a structural stress at the weld toe. This method works in situations where there is no clear definition of the nominal stress.

Further uses of local stress or strain approaches include both the use of macroscopic stress concentration due to the weld shape and local stress concentration at the weld toe region. To apply traditional methods of fatigue analysis to welds, an appropriate value of the stress concentration factor and residual stress is selected. We must, however,
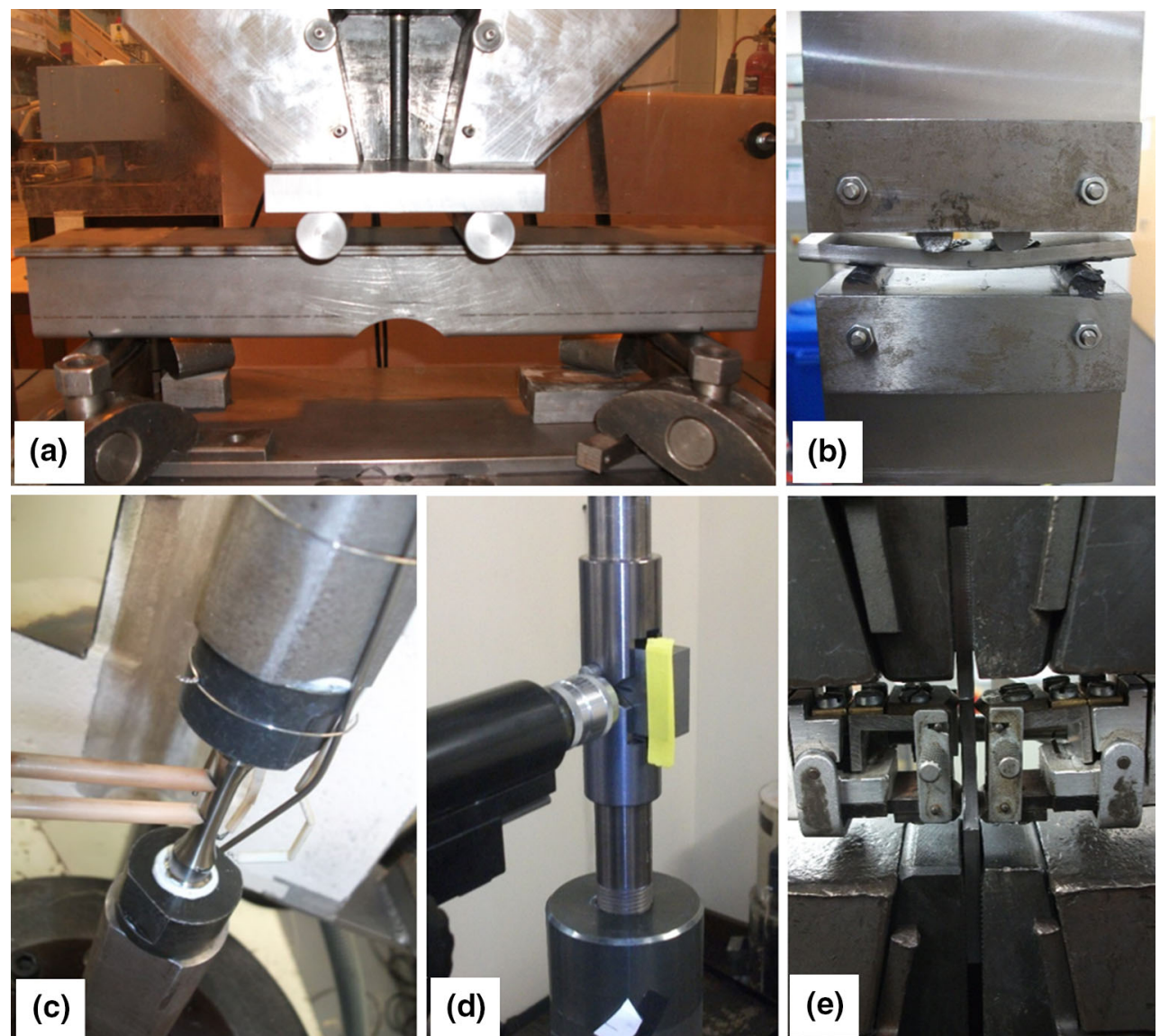

Fig. 2 Fatigue testing type used to asses welded structure durability: (a) four-point bended real-life structure, (b) four-point bending of a joined sample, (c) strain life (E-N) fatigue testing, (d) fracture toughness and (e) stress life testing with strain monitoring
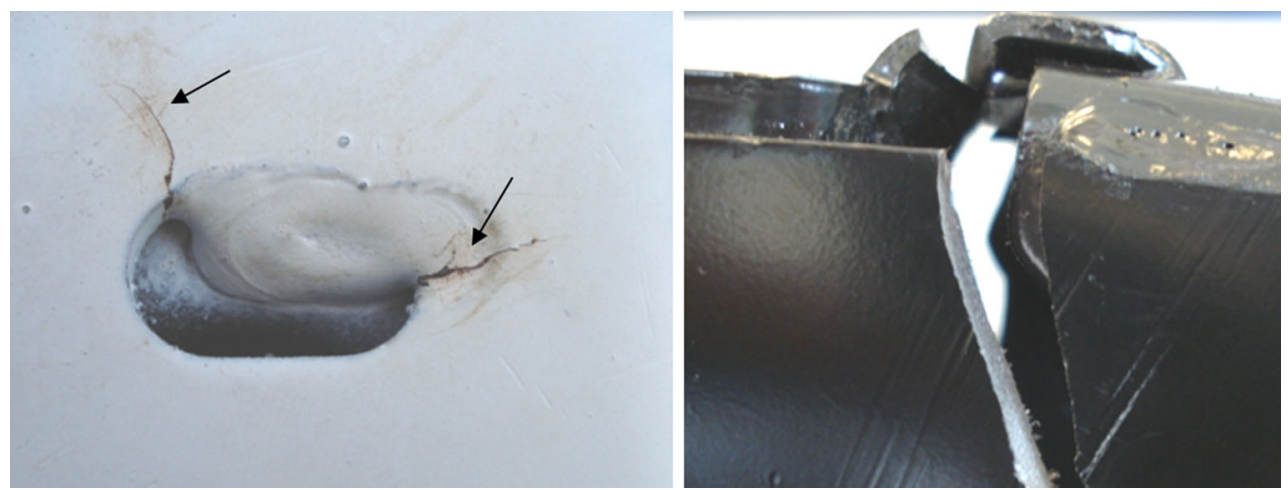

Fig. 3 Fatigue cracks initiating from the weld toe and subsequent structural failure of the application 
consider that it is the smallest stress raising radius which often produces the largest stress concentration factor. Because of this, there is a critical radius for fatigue that can be used to compute the fatigue notch factor. In this case, fracture mechanics models for crack growth are the most appropriate fatigue prediction mechanism.

The strength of welded joints on construction equipment depends on many factors that must be properly controlled in order to obtain high-quality welds. Residual stresses may be introduced through thermal gradients, which cause differential expansion and contraction patterns, the influence of clamping forces and the changes in yield strength with temperature.

Some advantages of welded joints over traditional bolts are that they are inexpensive and there is no danger of the joint loosening. However, as we will see throughout this article, some disadvantages of welded joints are that they produce residual stresses; they distort the shape of the piece and metallurgical changes occur in the HAZ.

\section{Fracture Mechanics}

The use of fracture mechanics may be recommended for cases where the standard stress life $(\mathrm{S}-\mathrm{N})$ fatigue life procedure is inappropriate. Typically, unusual structural faults or weld geometries do not have experimentally generated $\mathrm{S}-\mathrm{N}$ curves, definition of the periodicity of in-service inspections and assessment of the remaining life of cracked joints.

However, the stress range, stress ratio, mean stress and amount of damage are the main parameters contributing to the fatigue crack growth [4-7]. In linear elastic fracture mechanics (LEFM), the stress intensity factor ' $\mathrm{K}$ ' is the key parameter in the calculation of the fatigue damage. The distribution and intensity of stress and strains in the vicinity of a crack are obtained using either the LEFM or the elastic-plastic fracture mechanics. LEFM is a commonly used approach, which is based on the assumption that the plastic zone occurring at the crack tip is too small to significantly modify the stress distribution. There are three different basic modes of (1) cracking the opening, (2) sliding and (3) tearing modes.

The stress intensity factor $K$ depends on the loading, external geometry, and crack size and shape and may be expressed by the following general equation.

$K=\sigma \sqrt{\pi a Y}$

A furthermore elaborate expression for $K$ with explicit differentiation between membrane and bending stresses:

$K=\sqrt{\pi a}\left(\sigma_{m} Y_{m} M_{k, m}+\sigma_{b} Y_{b} M_{k, b}\right)$
Many proposals are available for calculation of the correction functions $Y_{m}$ and $Y_{b}$, accounting for various weld geometrical and loading configurations.

For predicting crack growth, a lot of mathematical and experimental investigation has been carried out. The Paris and Erdogan equation describes the crack growth rate in the intermediate region:

$\frac{\mathrm{d} a}{\mathrm{~d} N}=C_{0}(\Delta K)^{m}$

This equation can be used for finding the life of the component or number of fatigue cycles the component will withstand to fail.

$N=\int_{S_{0}}^{a_{f}} \frac{\mathrm{d} a}{C(\Delta K)^{m}}$

There are many equations based on the studies of Paris and Erdogan in the region of use full service time of the component under fatigue loading. This is particularly important toward weld fatigue analysis.

\section{Characteristics of Welds}

Welding of steel has been used for over 100 years as a process to replace bolted joints. The advantages of welding are numerous over that of mechanical linkages; however, the fatigue life of a welded component can be significantly reduced over that of un-welded component made of the same steel. Figure 4 shows a comparison of the $\mathrm{S}-\mathrm{N}$ fatigue life of an un-welded member, a stress raising notch and a fillet welded component. The influence of welds is as a

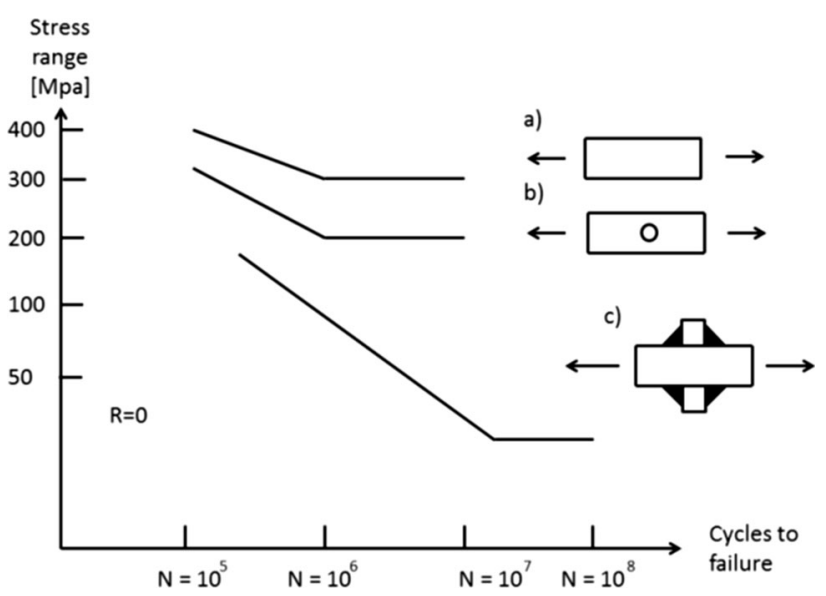

Fig. 4 Fatigue life comparison of (a) an un-welded member, (b) stress raising notch and (c) fillet welded member [8] 
result a significant effect toward reducing the fatigue life of the application.

During the welding process, stress raising features are produced around the weld. The significance of the stress raising effect of the weld is a result of numerous factors. This includes (1) the transition between weld material and parent steel, (2) position of weld in the plane, (3) the geometry and size of the weld and (4) the quality of the welding operation.

The metallographic structure of the region around the weld is altered with the formation of a heat-affected region. The welding process also produces residual stress of the tension type, which can also significantly influence fatigue life performance.

A significant issue with welded steel construction components is that (1) every weld produced will be different, (2) welded structures can feature regions that have weld defects and (3) no weld produced is ideal to a micron degree of precision. Welding is a skill that depends heavily upon the skill of the welder, their technique and the quality of the welding equipment as well as the welding process parameters that are used. Even if these are optimum, defects such as (1) misalignment of the workpieces, (2) nonmetallic inclusions and (3) increased residual stress can still be induced into the weld. On a construction site, welding is carried out manually using the gas metal arc welding (GMAW) or shielded metal arc welding (SMAW) processes. Figure 5 shows an example of a fillet weld and the components of the weld. Although the weld tow is usually the region where a fatigue crack will occur, a partial welded joint with defects can cause local stress concentration in the weld root.

On a construction site, fillet and groove welds are used in a wide range of structures. When the weld is in-service, fatigue failure occurs in an area where the stress concentration is higher. These stress intensity factors are higher than those of the average stress in the surrounding region. This is augmented for welds that do not fully penetrate the workpiece. Here, fatigue cracks can also grow from the weld toe and also from the weld root.

There are three methodologies when using S-N curves for calculating the fatigue life of welded joints: (1) nominal stress, (2) structural hot spot stress (SHSS) and (3) effective notch stress methods. Methods 1 and 2 are covered by international standards. However, these methods only focus on the weld toe region. This means that other methods need to be applied for weld root performance calculations. The effective notch stress method uses computational analysis and is able to cover effective stresses in the weld root as well as in the weld toe.

Due to the high complexity and higher accuracy of this method and due to the advanced in computer aided engineering, this method is now being used increasingly. Figure 6 illustrates the accuracy of the different methods, depending on the complexity of the geometry.

An example of the failure of a welded pipe flange is shown in Fig. 7. During failure analysis, the initiation of the fatigue crack was observed to have occurred at the weld root. The crack subsequently grew across the weld toe region as resulted in the ultimate failure of the structure.

If a weld is generated that produces insufficient penetration as shown in Fig. 8, then this can cause premature failure at a stress far lower than the designed stress of the application. Here, the fatigue crack initiated at the weld toe and grew along the bead of the weld before fracture. The quality of the weld is therefore highly important in order to generate high-quality and durable welds.

Figure 9 shows the different types of hot spot which introduces stresses in a steel plate. The type a hot spot is at

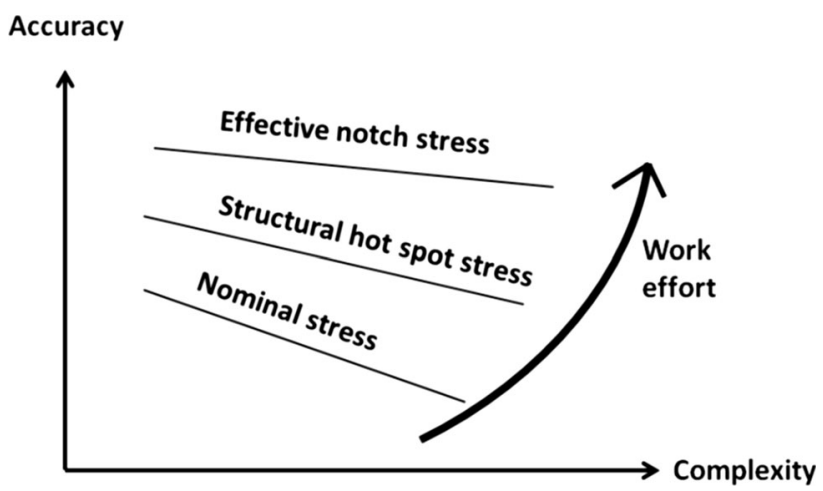

Fig. 6 Accuracy and complexity of the different welding methods
Fig. 5 Cross section of a fillet weld showing the (1) weld toe, (2) weld root, (3) weld leg and (4) the weld size [8]
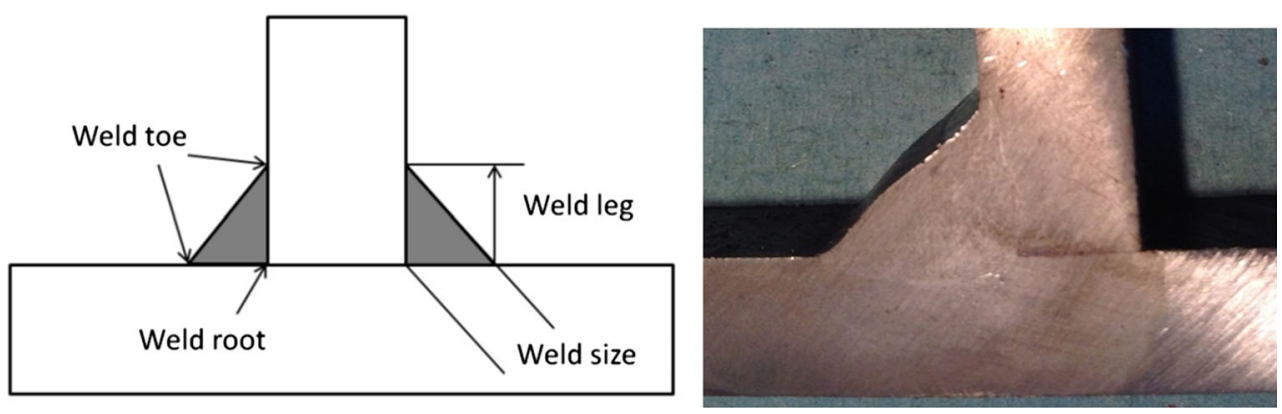
Fig. 7 Failure of a pipe flange weld with the initiation of a fatigue crack in the weld root region [9]
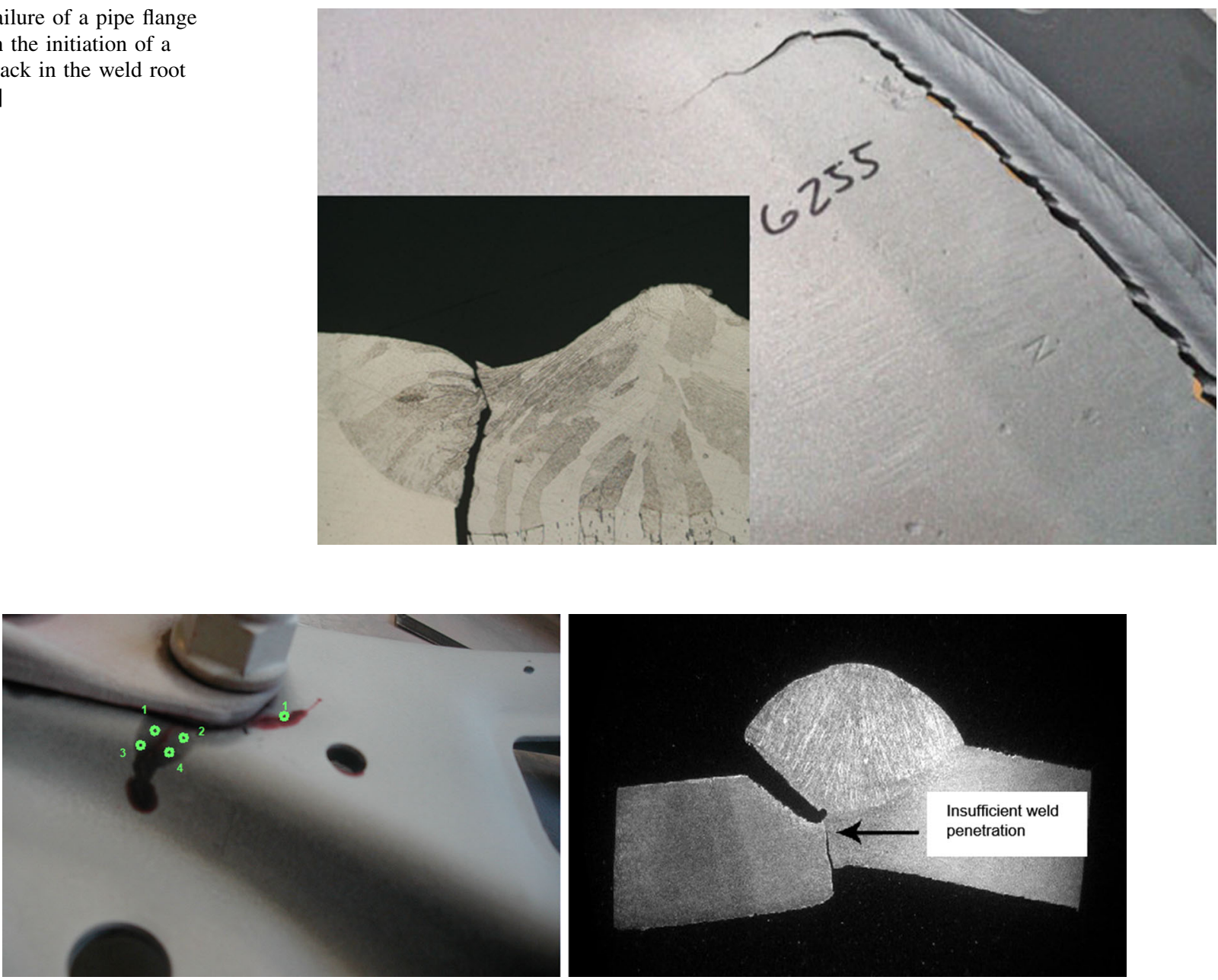

Fig. 8 Failure of a construction joint with the initiation of a fatigue crack and fracture due to insufficient weld penetration

the weld toe on the plate at the end of an attachment, type $b$ is at the weld toe at the plate edge of an attachment, and type $\mathrm{c}$ is at the weld toe along the weld of an attachment.

Type $\mathrm{c}$ is the more highly stressed of the two weld toes. Type a and type $\mathrm{c}$ are in principle the same, but due to the fact that influence of modeling is assumed to be greater at end of weld attachment, i.e., types a and b, they are separated. For type b, hot spots located at a weld toe on the plate surface of an ending attachment, and the plate thickness is not assumed to be a suitable reference parameter.

\section{Welding Defects}

Both the SMAW and GMAW welded process are used heavily in construction projects. Each has advantages and disadvantages, which are often based upon the weld type and the location of the project. SMAW processes as shown schematically in Fig. 10 require the striking a low-voltage, high-current arc between a consumable electrode and the

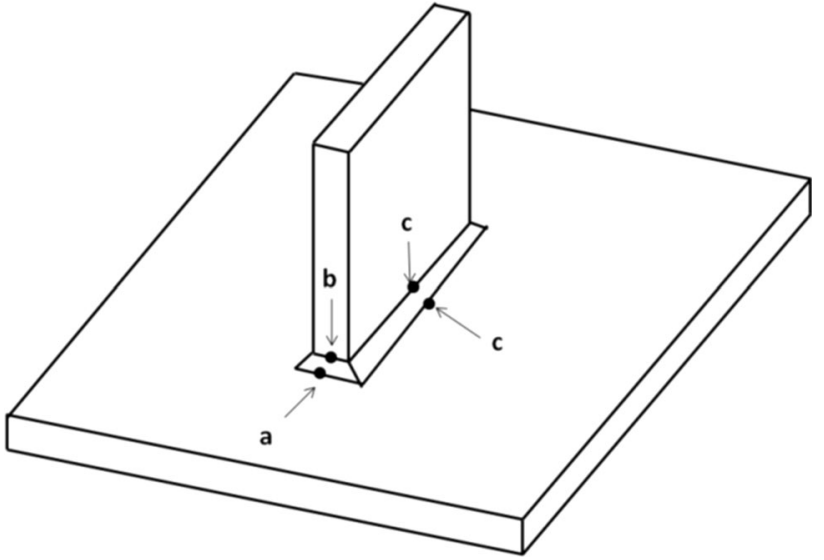

Fig. 9 Different hot spot types on a welded component (a, b and $\mathbf{c})$ [8]

steel. The intense heat generated with this arc melts the steel. The direction of the current deposits the electrode material to form the weld and join two separate steel components together. The characteristic properties of the 
Fig. 10 Schematic of the shielded metal arc welding process [9]

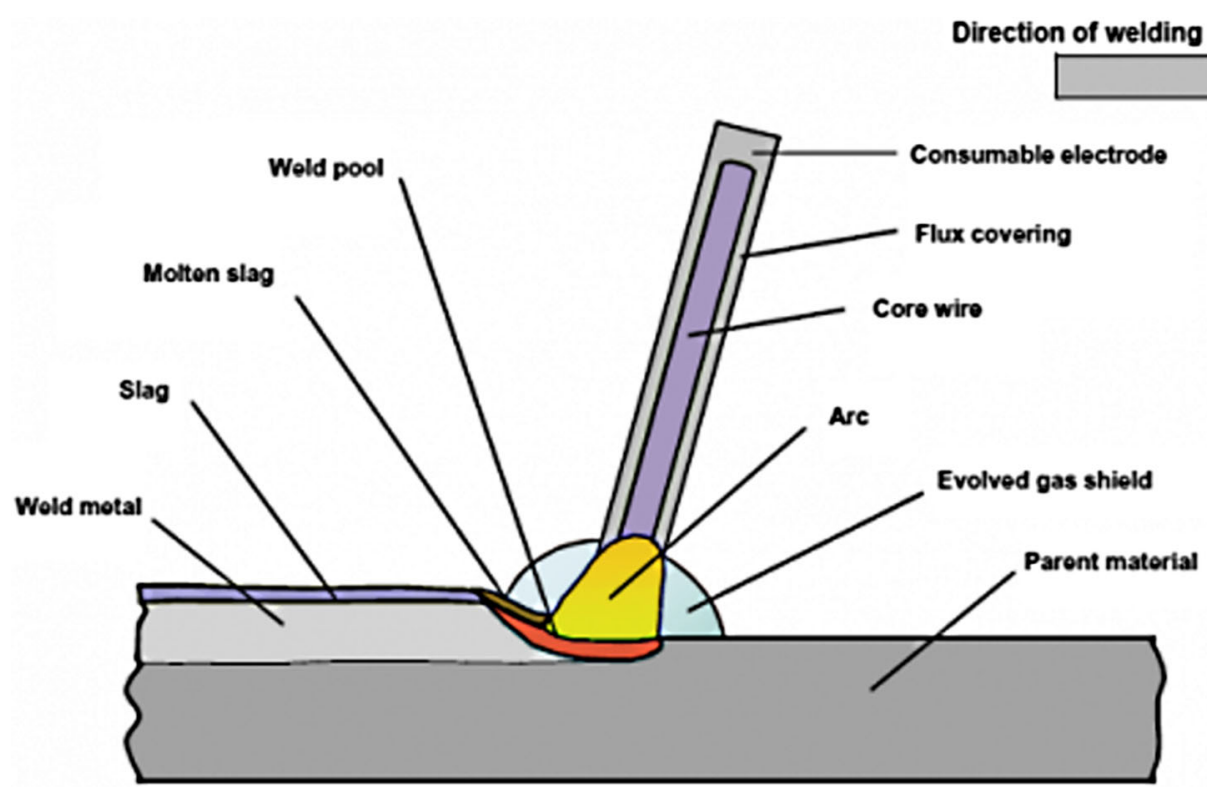

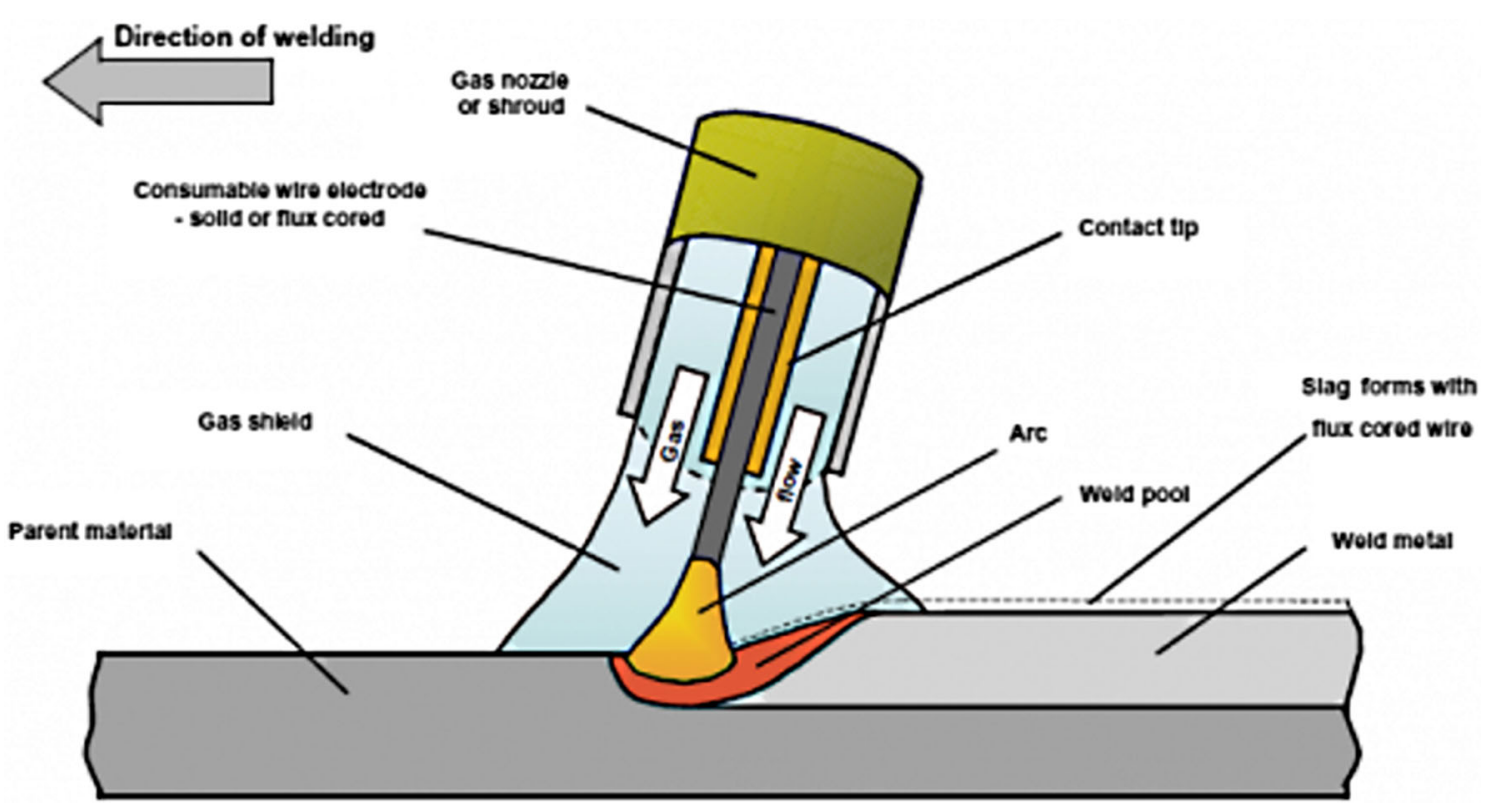

Fig. 11 Schematic of the gas metal arc welding process [9]

steel being welded and the joint type dictate the welding parameters, electrode type and the procedure that needs to be followed to obtain a structural weld.

SMAW is the most widely used process on site due to its simplicity and due to that fact that no cylinder of shielding gas is required. The arc is struck between the steel and the flux-coated consumable electrode. The flux covers the hot weld deposit and shields it from the environment. The solidified slag is subsequently removed by chipping it from the top of the weld. The weld is then subsequently cleaned with a wire brush.
During the process of producing of producing a multipass SMAW weld as shown in Fig. 11, it is important to ensure that any slag remaining in the weld is removed before the subsequent bead is generated. This can often be time-consuming and difficult especially when welding at an angle, or when welding in cramped conditions which are inaccessible. The importance of removing any slag is paramount due to minimizing the chances of nonmetallic inclusions being left in the weld.

GMAW welding processes as shown in Fig. 11 use an uncoated continuous wire, which is shielded from oxide contamination by gas that is fed through the welding torch 

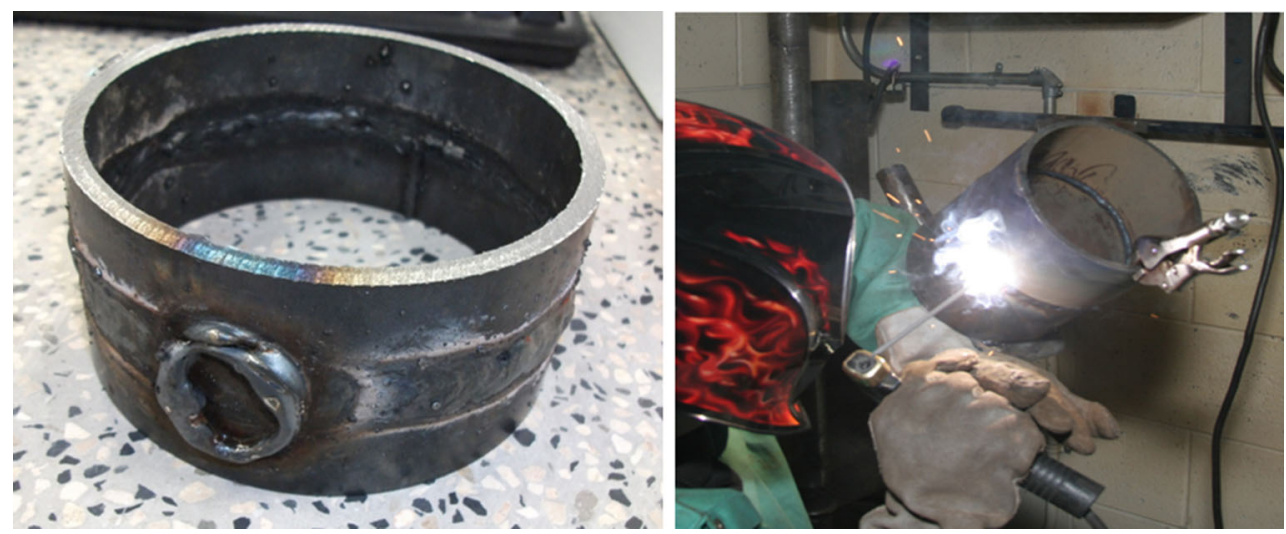

Fig. 12 The author using the SMAW process to generate a multipass weld on a section of pipe in the angular position
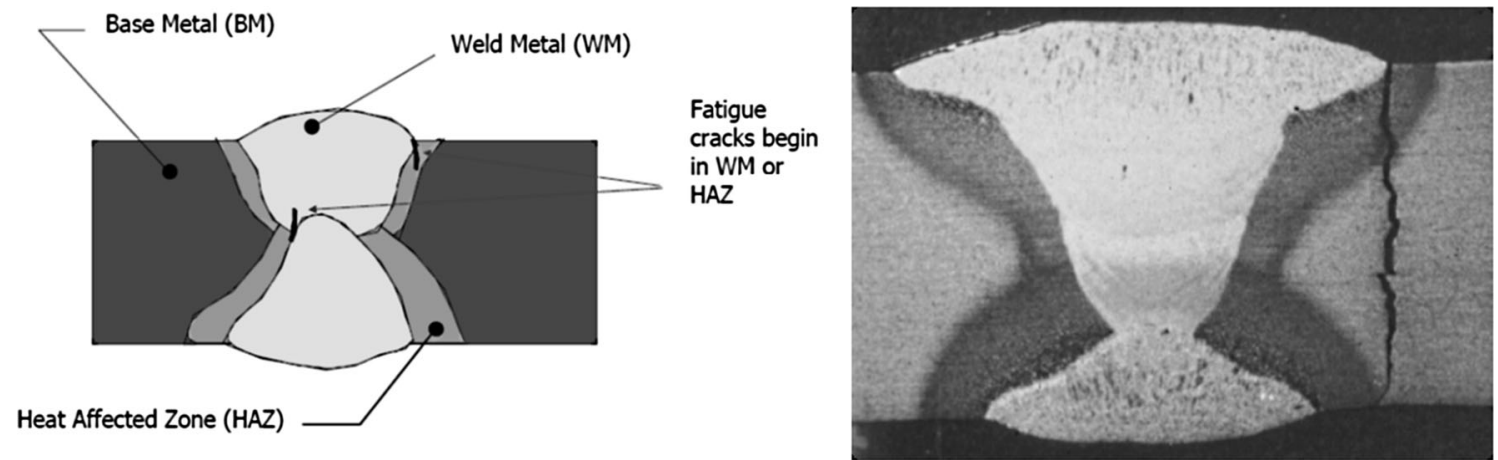

Fig. 13 Transverse profile of a multipass GMAW showing the difference in the metallurgical properties that are formed [8]

tip. The mode of metal transfer can be altered between (1) spray, (2) globular, (3) short-circuiting and (4) pulsed arc. This is varied by adjusting the amperage and the shielding gases, which depend on the welding position and the type of joint (Fig. 12).

During the welding process, defects produced can extend deep into the weld. For this reason, defects must be avoided. During the welding inspection process, when a weld defect is detected, it must be removed, with a weld repair being carried out. Figure 13 shows a multipass weld produced using the GMAW process. Here, two welds have been generated into a groove in which the profile of the weld shows (1) the base material, (2) HAZ and (3) weld material.

Even when an optimum weld has been produced, the crack will often initiate in the welded metal on the heataffected zone, but not in the base material. This is because the heat-affected material consists of harder martensitic material, and due to the volume change, there is the formation of tensile residual stresses left behind after the process.

There needs to be serious concern shown to the design of the weld as shown in Fig. 14. A good weld design will display local stress concentration at the weld toe region.
However, if a weld is generated that is designed poorly, then the stress can be concentrated across a range of geometries or results in increases in the stress intensity at an intense point, which can result in premature failure.

The common weld defects are shown in the following examples. A longitudinal, transverse or crater cracks as shown in Fig. 15 can occur at any point on the weld bead of the weld, (1) transverse to the weld (2) longitudinal to the weld and (3) form from craters on the weld. Here, a crack can propagate quickly through the weld and result in premature failure.

Figure 16 shows a stress raising undercut at the edges of the weld. Dirt, scale and oxides can also present in the undercut area, which can cause further defects. The problem is that both groove and fillet welds made in the horizontal position will usually have undercut on the upper part of the weld.

Porosity or worm holes in the weld as shown in Fig. 17 are a significant defect. Linear aligned porosity is usually found near the bottom, along the sidewall or at weld intersections. Care must be taken during the welding process to ensure that the correct speed and angle is maintained during the formation of the weld. If a worm hole is generated, then it is important not to weld a patch 
Fig. 14 Weld design types and the difference in weld stress concentration

\section{Good Weld Design}

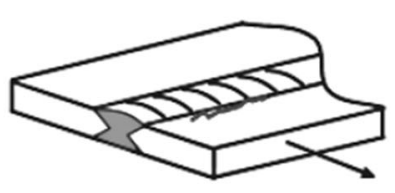

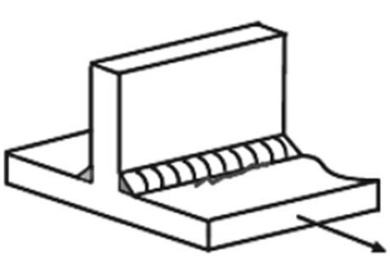

Local stress concentration at the weld toe region

\section{Poor Weld Design}
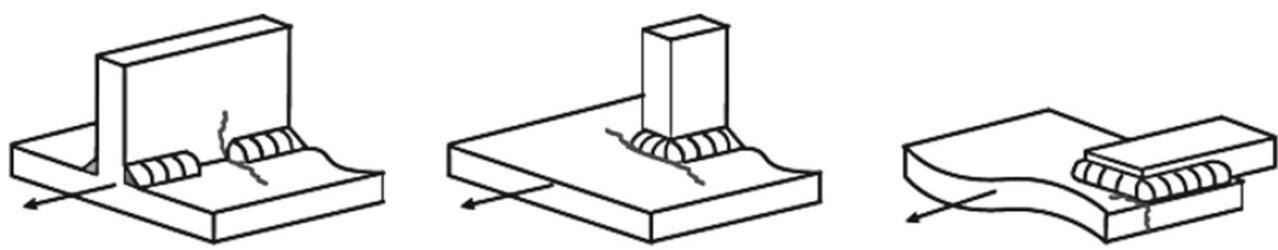

\section{Stress concentration across a range of geometries}
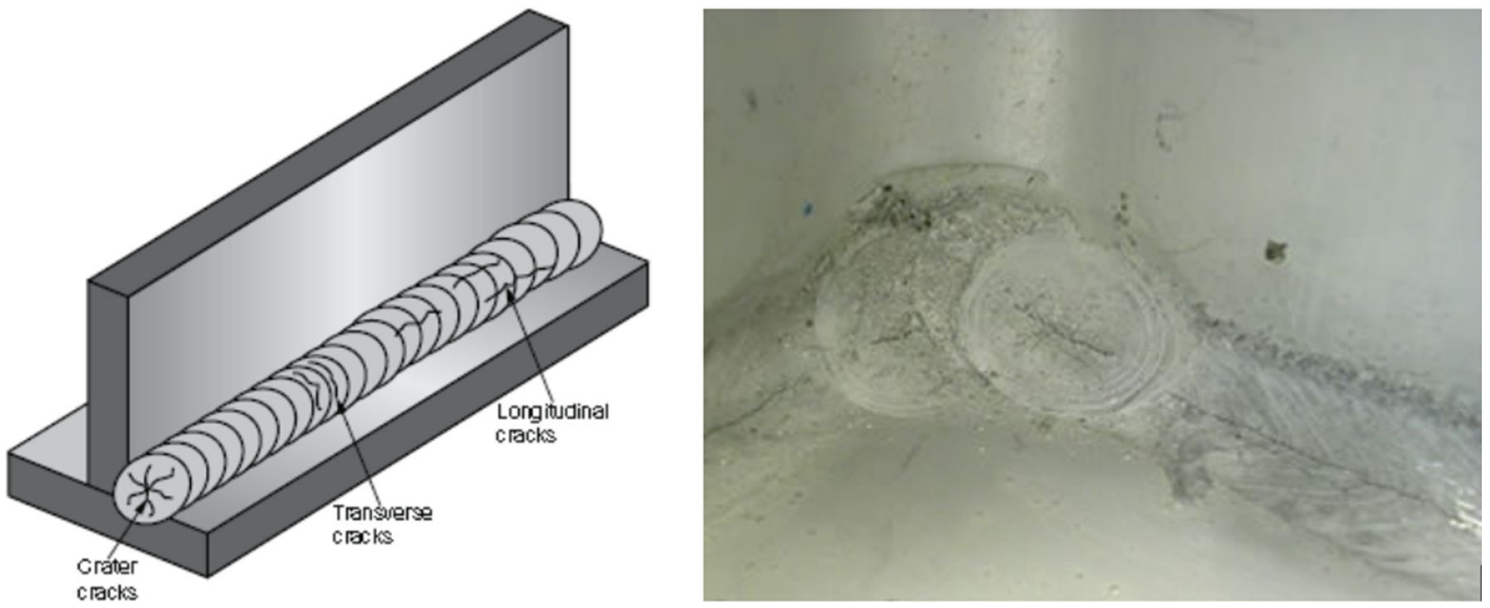

Fig. 15 The different cracks that may be found on welds

Fig. 16 Undercut on a fillet weld, which can occur on either edge of the weld
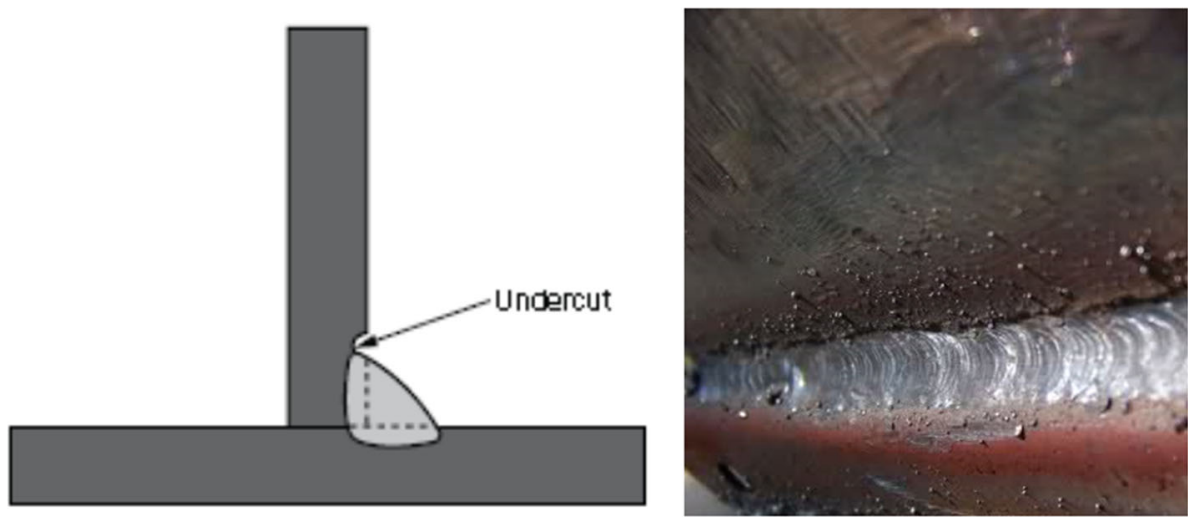

over the hole as this can introduce a larger HAZ. Firstly, remove the pore and inspect the weld by radiographic or ultrasonic inspection to ensure that the porosity has been completely removed before repairs are commenced. Subsequently, fill the deepest part of the pore recessed area first and maintain each layer of weld level until the area is filled. 
Fig. 17 Isolated porosity can occur in any portion of the weld
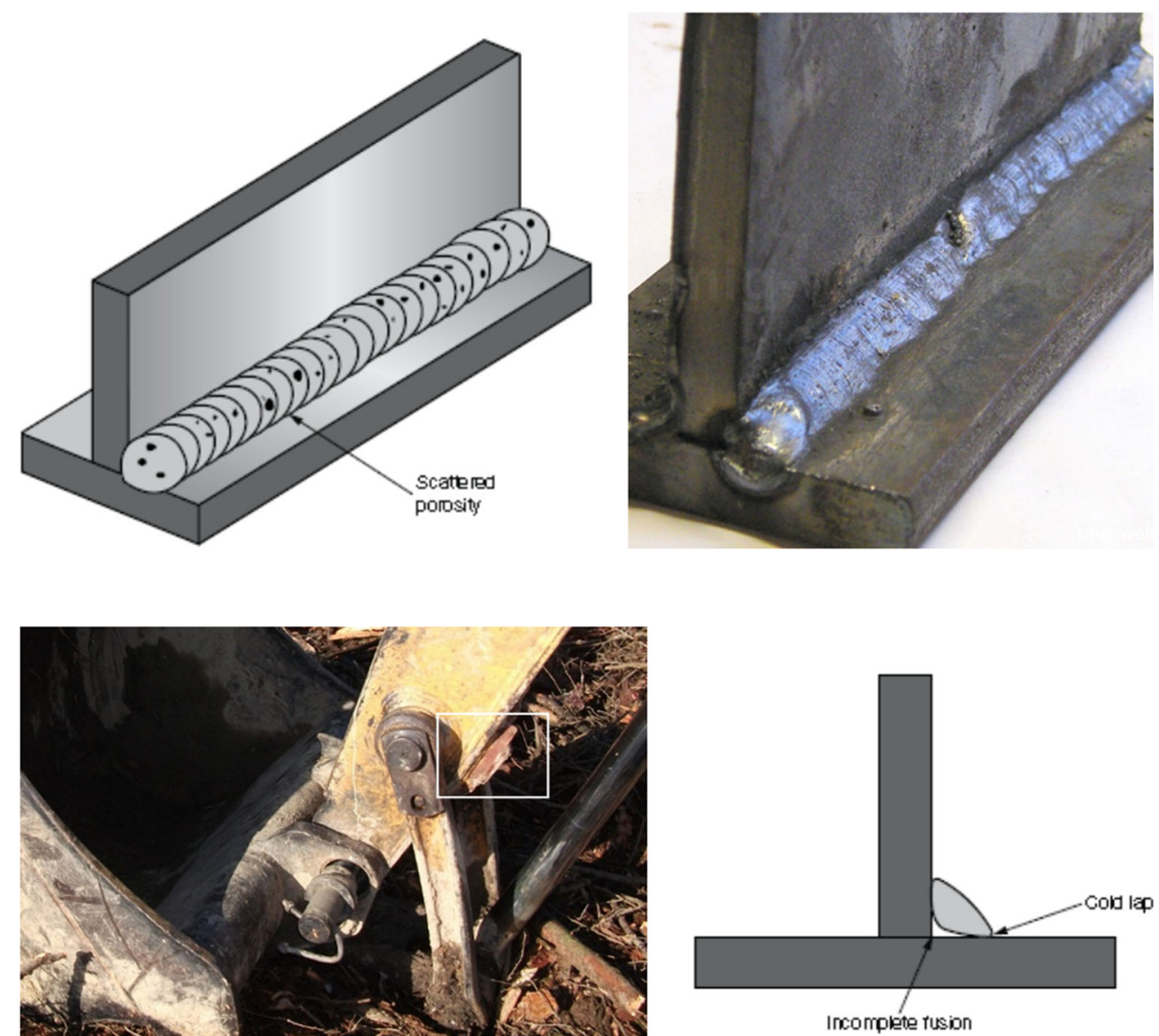

Fig. 18 Fillet weld cold laps are usually located on the bottom side of the weld. Here, an excavator has been poorly repaired in the field, and due to the generation of a cold weld, the structure failed soon after

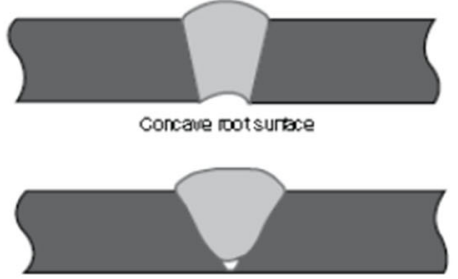

Incomplete penetration
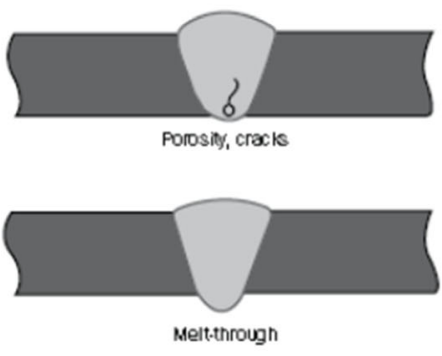

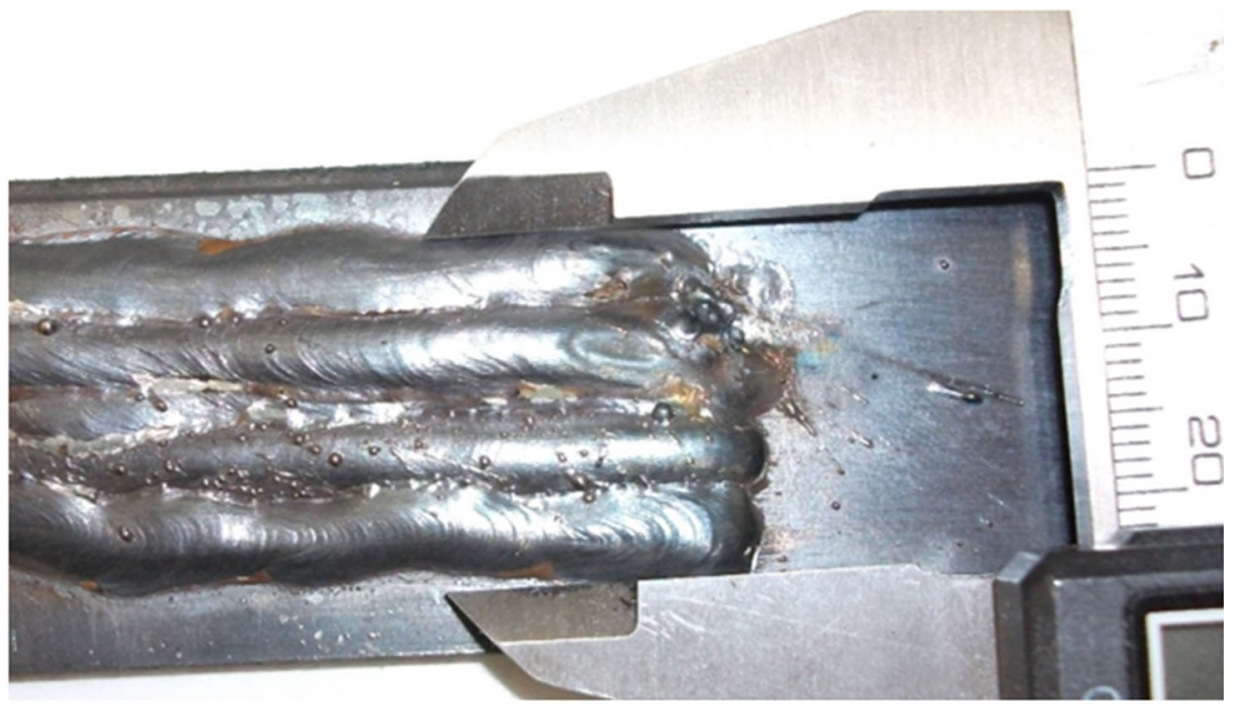

Fig. 19 Incomplete penetration defects shown can occur on the root side of the weld. Here, we can see incomplete penetration in a letterbox infill

Cold laps as shown in Fig. 18 are areas of the weld that have not fused with the base metal. Cold laps can occur on fillet welds or butt welds, usually as a result of a current that is too low, by using down-hand welding, the environment or by using a high welding speed. It is important to remove the entire weld by grinding it back and 
Fig. 20 Internal defects shown can occur in the interior of the weld. Here, six weld passes have been used to repair a plate steel structure. The welds look of high quality; however, radiographic testing revealed an oxide pocket had been produced between the second and third weld bead
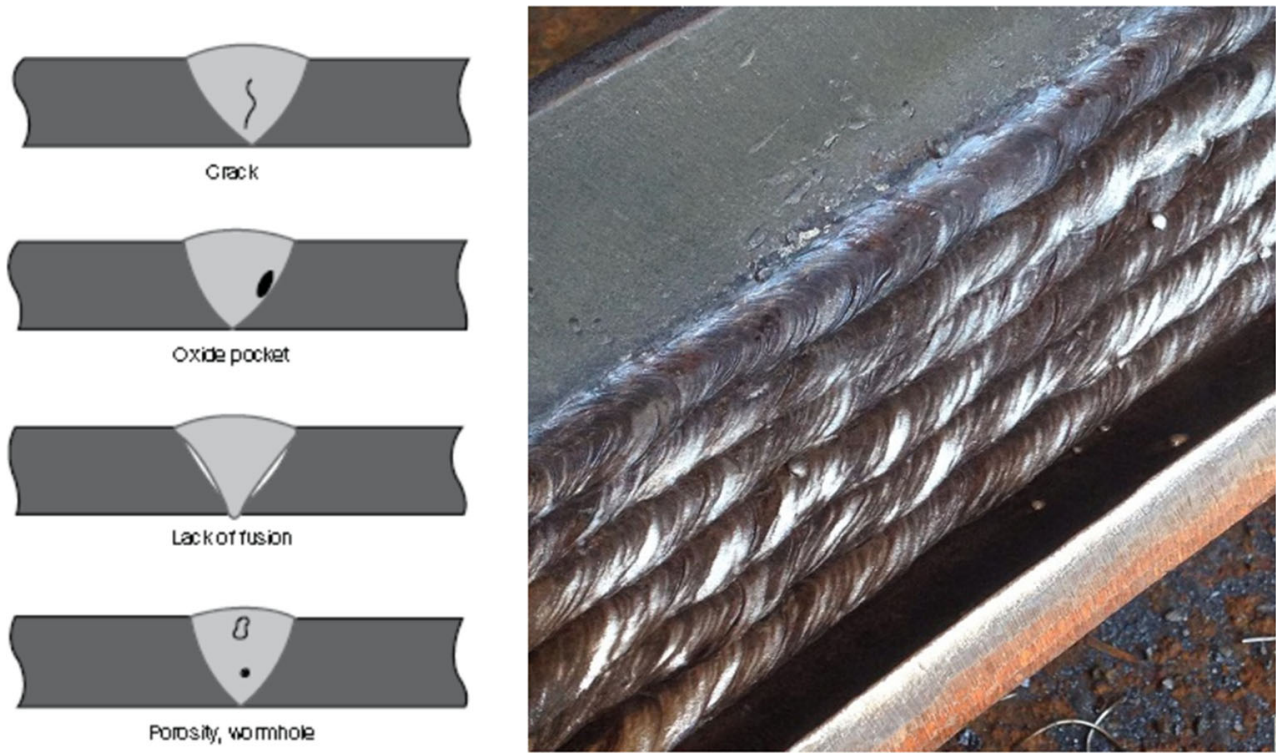

subsequently check to ensure that the overlap material has been removed. When re-welding, ensure that the appropriate process parameters and technique are used.

Incomplete penetration occurs on the root side of the weld as shown in Fig. 19. If this process occurs, then it is paramount importance to remove all of the region, including the heat-affected zone by grinding. Since surface oxides form in this area during welding, it is important to clean the repair area before re-welding.

Internal defects as shown in Fig. 20 may or may not extend to the surface and can be very difficult to detect. Even though a weld looks of high quality, sometimes it may be important to use either radiographic or ultrasonic testing to determine internal defects.

\section{Conclusions}

In this manuscript, the problem of the failure analysis of welded constructional steel components has been introduced. The variables influencing weld fatigue life can be through the magnitude of notch root stress and through the properties of the notch. Because of factors such as the applied stresses, the degree of warping, residual stresses, the weld geometry and size as well as any weld defects influence the notch stress. The fatigue behavior of a weld is subsequently controlled by the local stress at a notch.

It is crucial to investigate type and magnitude of the loads which influence each part of the weld. The strength properties of the material and the weld must match the minimum requirements set for a reliable design. Further to this, welding should be carried out according to current international standards.

Failures in constructional steel welded structures can lead to catastrophic structural failure. Therefore, it is important to consider the factors that influence weld failure and ensure there is appropriate mitigation toward the formation of the factors.

\section{References}

1. C.E. Inglis, Stress in a plate due to the presence of cracks and sharp corners. Trans. Inst. Nav. Arch. 55, 219-242 (1913)

2. A.A. Griffith, The phenomena of rupture and flow in solids, Linear Networks and Systems (Book style) (Wadsworth, Belmont, CA, 1993), pp. 123-135

3. Paris, Erdogan, A critical analysis of crack propagation laws. J. Basic Eng 85, 528-534 (1963)

4. J. Schijve, Fatigue of Structures and Materials (Kluwer Academic Publishers, Dordrecht, 2001)

5. A. Blake, Practical Fracture Mechanics in Design (Marcel Dekker Inc., New York, 1996)

6. D. Broek, Elementary Engineering Fracture Mechanics, Chapter 2, 10 (Kluwer academic Publishers, Dordrecht, 1986)

7. G.G. Chell, Developments in Fracture Mechanics, vol. 1 \& 11 (Applied Science Publishers Ltd., London, 1979)

8. Compendium UK 2006-93 Faculty of Engineering Science and Technology NTNU Trondheim Norwegian University of Science and Technology

9. Short Term Course, Fatigue Design and analysis of Ships and Offshore structures (Ocean Engineering Department, IIT Madras, Chennai, 2007) 